\title{
LETTERS
}

\section{Effects of the Full Service Family Practice Incentive Program}

I am responding to the letter to the editor by Lavergne and colleagues. ${ }^{1}$ They note similar findings to ours for the overall Full Service Family Practice Incentives Program (FSFPIP) when they note that "We observed that patients with incentives had lower costs and hospitalizations on average, as well as higher continuity or 'stickiness'." They go on to state that "this was true even before incentives were billed and so this difference cannot be casually attributed to the incentive payments." With regard to causality, unless one does double-blind randomized controlled trials (RCTs), preferably with a crossover design, one cannot begin to claim causality. This applies to both of our approaches. We have never claimed causality but do claim a strong and consistent association.

With regard to the people who received incentive payments having lower costs, even before they used the incentives, we were aware that the early adopters of incentives were often well-established physicians who tended to have patients with higher levels of attachment and, therefore, lower costs and utilization rates. ${ }^{2,3}$ We dealt with this by adjusting, or standardizing, for differences in attach- ment levels between those who billed and did not bill incentives.

Finally, readers should be aware that the concerns presented by Lavergne and colleagues simply come down to a debate about two different, but acceptable, quasi-experimental research methods, each with its own strengths and weaknesses. For our part, we can simply say that we took numerous steps, including conducting a series of methodologic substudies, to ensure that our evaluation was as rigorous as possible.

\section{Marcus J. Hollander PhD}

President

Hollander Analytical Services Ltd., the evaluators for British Columbia's Full Service Family Practice Incentives Program (from 2008-2013), Victoria, BC

- Cite as: CMAJ 2017 February 13;189:E252. doi: $10.1503 / \mathrm{cmaj} .732855$

\section{References}

1. Lavergne MR, Law MR, Hurley J, et al. The authors respond to: letters by Catherine Clelland and Shelley Ross [letter]. CMAJ 2017;189:E251.

2. Hollander MJ, Kadlec H. Financial implications of the continuity of primary care. Perm J 2015; 19:4-10.

3. Hollander MJ, Kadlec H. Incentive-based primary care: cost and utilization analysis. Perm J 2015; 19:46-56.

Competing interests: See affiliation. 